\title{
Designing electronic shops, persuading consumers to buy
}

\author{
Dormann, Claire
}

Published in:

Proceedings of the 26th Euromicro Conference

Link to article, DOI:

10.1109/EURMIC.2000.874411

Publication date:

2000

Document Version

Publisher's PDF, also known as Version of record

Link back to DTU Orbit

Citation (APA):

Dormann, C. (2000). Designing electronic shops, persuading consumers to buy. In Proceedings of the 26th Euromicro Conference (Vol. 2, pp. 140-147). https://doi.org/10.1109/EURMIC.2000.874411

\section{General rights}

Copyright and moral rights for the publications made accessible in the public portal are retained by the authors and/or other copyright owners and it is a condition of accessing publications that users recognise and abide by the legal requirements associated with these rights.

- Users may download and print one copy of any publication from the public portal for the purpose of private study or research.

- You may not further distribute the material or use it for any profit-making activity or commercial gain

- You may freely distribute the URL identifying the publication in the public portal

If you believe that this document breaches copyright please contact us providing details, and we will remove access to the work immediately and investigate your claim. 


\title{
Designing Electronic Shops, Persuading Consumers to Buy
}

\author{
Claire Dormann \\ CTI, Technical University of Denmark \\ claire@cti.dtu.dk
}

\begin{abstract}
The purpose of this article is to show how to design persuasive and successful web shops. An approach to commercial site design that draws on theories of visual persuasion is proposed. In this paper, we will focus on the role of emotion. Images in an ad are typically meant to create some emotional disposition toward the product, or social cause. The importance of emotions in the on-line shopping context is highlighted.

Mechanisms found in visual persuasion showing ways of capturing the audience's attention and emotions are discussed. To illustrate these mechanisms, examples drawn from electronic shopping are considered. To strengthen the discussion, an evaluation of shop home pages, situated within the perspective of visual persuasion is presented. This study has given some indications that viewers form distinctive emotional impressions from shop designs. Thus, by building on visual persuasion theories, we can learn how to design seductive web shops.
\end{abstract}

\section{Introduction}

Consumer electronic shopping appears to be one of the most attractive and fastest growing areas of Internet technologies. Many users access retailing home pages, but fewer pursue their visit, and only very few buy online. Many transactions are started but never completed.

Some answers are found by looking at website designs: sites are often difficult to use, and have many errors, hindering the purchase process. Moreover, sites are often unattractive and unimaginative. If by any chance consumers browse through a site, they often face endless rows of products that are, at the least, not very pleasing, tempting nor conductive to purchase. Sites should be effective in appealing to and attracting visitors, and persuading them to buy. We need to turn to visual persuasion in order to find out how to achieve these goals.
An approach to commercial website design that is proposed, draws on notions of visual persuasion grounded in advertising research, and is seen in the work of Messaris [1], Forceville [2], and Durand [3].

Wares are exposed to viewers' eyes. Images are used to capture viewers' attention and imagination; a whole range of visual messages can entice, exhort and explain. Many advertising campaigns rely on emotions created by visual stimuli to change attitudes. Similarly, we should rely on emotions to attract visitors and sell goods.

It is thus fundamental to understand the role of emotions in the shopping context. To do so we will turn to the field of consumer behaviour. Consumer studies have shown that the emotional component is more important than the utilitarian component of some types of consumption (music), types of purchase (impulse buying), and types of purchasing situations (gift). In these cases, emotions play an important role in the decision making process. Consequently, creating an appropriate emotional environment could trigger the purchasing decision.

The goal of this paper is to show how to design persuasive electronic commerce sites through theories and methods pertaining to visual persuasion. This paper first focuses on the role of emotion; thus the function of emotion in consumption is first reviewed. Mechanisms that can help to enhance and create effective design will then be introduced. Some of these mechanisms consist of manipulating image characteristics to enhance product display, such as using characters to create empathic links with consumers or using humour as appeal. These mechanisms are illustrated by examples found in electronic commerce. The argument is further illustrated by two small case studies: Parvo and FoodNet. To strengthen the discussion, an evaluation of electronic shop home pages is presented. This study has given some indications that viewers form distinctive emotional impressions from website shop designs. 
This paper contributes to the development of effective electronic shops and should stimulate further studies in the role of visual persuasive discourse within electronic commerce.

\section{Emotion and consumption experience}

In this paragraph, we will present the role of emotions in consumption, stressing instances in which the emotional component is specifically important, and describe consequences for the shop design. Emotions represent motivational phenomena with characteristic neurophysiological, expressive, and experiential components [4]. Consumption emotion has been used to refer to the set of emotional responses elicited during consumption experiences, for example, during product acquisition or usage [5]. Expressions of pure enjoyment, excitement, surprise, captivation, escapism and spontaneity are aspects of consumption emotion.

Prior studies found that emotions play an important role in problem solving and decision making by providing information on the emotional desirability of the options available, thereby reducing and limiting reasoning to only those that induce positive feelings [4]. For example, pleasurable affect increases efficiency in a car choice task [6]. Thus, electronic shops need to present products in an appealing and attractive manner. We need to dispose consumers favourably toward products.

The emotional component is more important in some types of purchase and types of purchasing situations. For some products, such as aesthetic objects, these intangible, symbolic attributes can be key determinants of brand selection. In those instances where emotional desire dominates utilitarian motives, creating an appropriate emotional environment might trigger the purchasing decision.

Purchase decisions can be based on symbolic elements of products or services, as conveyed in pictures and processed as imagery, rather than on their actual features [7]. Thus, paying attention to picture effectiveness can be a key factor to the success of electronic shopping. We attend more to visual stimuli that are more arousing by their greater levels of properties like novelty, surprise, or incongruity. Boredom is as much a threat in electronic shopping as it is in advertising. Therefore, it is useful to discuss how to manipulate images and their characteristics in order to create powerful and original messages (see 3.1)

Moreover, emotions associated with consumer activities may provide value directly [8]. Emotions like pleasure and arousal are important components of intrinsically valuable time. This means that consumers should enjoy their visit and enjoy browsing through the website. Consumers report being delighted over becoming immersed in a store and the same should apply to an electronic store. We prolong activities that make us feel good and keep our interest, and thus it can be crucial to create an appealing site. We will therefore further discuss how to make an appeal by focusing on a specific strategy, the use of humorous appeal (see 3.3).

\section{Creating and expressing emotion}

The world of advertising is populated by fantastic images. Products kaleidoscope past our eyes in dramatic visual styles and a multitude of imaginary characters dance through situations ranging from sensual to playful. Analysing examples of advertising and websites through the perspective of visual persuasion gave us indications of how to provoke emotions and to create persuasive messages. Some of the mechanisms used to that affect are presented here: manipulating image characteristics, the importance of human character, and creating a humorous appeal.

\subsection{Manipulating image characteristics}

Seductive messages can be created by manipulating design factors such as colour and line, but also by overlapping and cropping of forms, using illusory space or by using the dynamics of negative-positive relationships. Colour is often associated with specific emotional response [9]. Through the subtle articulation of light and shadow an entire image can be implied. The idea of formulating an image by only addressing its background changes the habitual approach toward seeing, and thus attracts attention [10]. In fact, each visual element offers multiple possibilities for contrasting visual information [11].

Altering, rearranging, changing or redesigning a commonplace image can create a new impression to capture an audience's attention. We can present a proposition in a fresh way so that the audience thinks about a familiar issue from an unexpected perspective. In this way we can break through habitual perception, scepticism, and boredom [12].

Too often, in electronic retailing, rows of products succeed one another. In Majestic-choices, a web shop selling coffee (Fig. 1), three different coloured packs of coffee are depicted in an image, where at the bottom corners, beans and a cup of coffee are added. Here, a complex visual message is given in a single image.

The breadth of the products is suggested by the different coloured packs. The cup of coffee and beans 
relate to a multi-sensory experience provoked by coffee, representing the taste and aroma of coffee, thus suggesting the pleasurable experience of sampling coffee.

Another example concerns the Lancome site, where one could expect picture after picture of various lipsticks in various shades, one looks at a more sensual and unexpected image representing coloured lips (Fig. 2). By using non-ordinary expression the designer creates an element of surprise and stimulates the viewer's interest.

In this third example, Maison Blanche's home page

(Fig. 3). Luxurious and expensive objects are used to represent the shop and shop content (mansion, perfume, mirror, etc.). Characters of a smiling little girl and a man are pictured. The utilisation of a man cooking is unusual in the world of advertising. The image of a modern and elegant shop is conveyed through the choice and arrangements of visual stimuli. The mood of the pictures is determined by many subtle factors. Most important is the choice of objects and props, as well as finding the right environment in which to display objects.

Rhetoric techniques, like accumulation, utilised in the Maison Blanche site (i.e. the expansion of a topic through the assembling of relevant particulars), or metonymy in the Lancôme site, (the substitution of terms suggesting an actual relationship) can be used to illustrate products or product characteristics in innovative ways [13]. Moreover, metaphors are prominently contained in many visual representations to act as the vehicle for transferring abstract qualities to products.

\subsection{Character in the representation of emotion}

In websites for electronic shops, the portrayal of people, although uncommon a while ago, is becoming more widespread. This is not only happening in the retail sector, such as in the fashion industry (e.g. www.redoute.fr) but also in services catering to human needs, such as travel (e.g. www.spies.dk), education (Napier University, www.napier.ac.uk, "All types of programmes for all types of people") and telecommunication (Nokia, www.nokia.dk, "Connecting people"). For example, Napier University's home page portrays students relaxing, or talking to a member of staff. Moreover, their logo consists of five amusing portraits having specific characteristics and expressions.

Human beings are experts at interpreting facial expressions and body language, and consequently they are profoundly susceptible to emotions, moods and actions of others [14]. By involving people, advertising images reproduce real word visual cues that are associated with a variety of emotional responses. For example, photographs of baby-faced male subjects correlated with perceptions of honesty, warmth and naiveté. Viewers responded to cliché images of children and cute animals [15]. The viewer's involvement with the picture can by manipulated by degree of proximity, or angle of view.

The term empathy as used by psychologists to mean "imaginative projection" of one's own consciousness into another human being. Empathy with advertising and electronic commerce messages and personas may enhance consumer self image, and express consumer values [16]. Visual persuasion takes advantage of these phenomena and uses happy people to make us more cheerful, or presents excited groups to arouse one's curiosity (see Maison Blanche or Parvo, in 4.1).

Many ads are based on experience of personal gratification. A typical example is this dynamic picture of a rollerblader, invoking skills and excitement (www.skatepro.dk), or (www.rollerblade.com). Sometimes the depiction of characters is replaced by the utilisation of animated objects, symbolising happy consumers (www.hersheys.com, www.mayo.com, see FoodNet, 4.2).

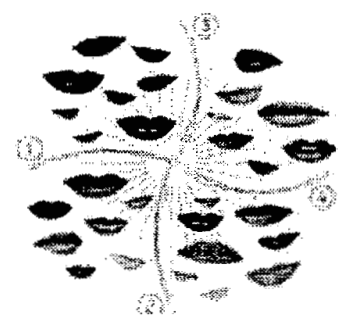

Figure 2. Lancôme

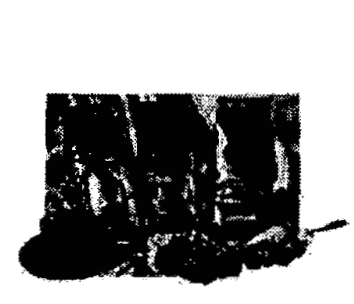

Figure1. Majestic-choices

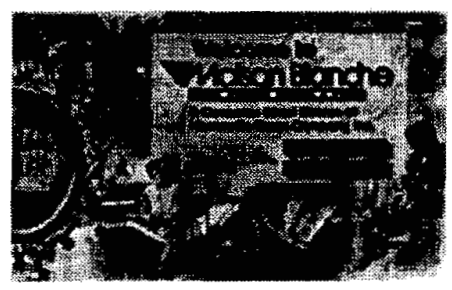

Figure 3. Maison blanche 


\subsection{Humour and fun as appeal}

An appeal is something that makes a product particularly attractive or interesting to consumers. Product appeal often relies on the expression of variety by associating products with different situations and persons. Appeals can be emotional, for example, fun (game), elegance (fashion), romance (perfume), luxurious (household items), or trustworthiness (bank).

An appeal can be achieved by humorous messages or messages providing consumers with challenging puzzles to solve for their edification and delight. Humour is effective in arousing attention. Humorous ads are thought to blend pleasure and persuasion by providing an aesthetic reward to the audience, that is, enjoyment of the ad itself [17].

Some sites such as Joe Boxer (www.joeboxer.com), a promotional site for underwear, are based on humorous and provoking messages. These messages are delivered through games, inventive images, and features based on perfect knowledge of the computer medium [18]. Kilroy (www.kilroytravels.com), a student travel agency, illustrates its slogan "Go before its too late, for young people under 26 and students under 33", by picturing a male character going through the infant stage to vigorous and active adulthood (21-27) to a decrepit character (at 33), see Fig.4.

There are many ways of creating humorous communication, for example, by use of a specific technique like caricature, pun, or irony. Irony as a technique entertains an audience clever enough to disentangle real meanings: people feel special when they solve a puzzle or joke. Irony may be included to support a brand's personality or call out to a particular target.

Visual puns occupy the same place as word games. In the Lancôme site, a page inciting consumers to buy (a perfume), the words (love, sun, smile etc.) formed a bouquet of flowers, a symbol of romantic love. The design is also a kind of visual poem, Poême being the name of the perfume.

Caricature is a well-known technique where someone's features are exaggerated. One example, a caricature of the Beatles, has been found in a music website (www.rockmine.music.co.uk/char.html). Caricature is often used to reflect specific characteristics of persons or products. A bad tempered lawyer will take on some of the features of a bulldog. For a site selling hot sauce (www.aussiehot-headz.com.au), the burning power of the sauce is symbolised by exaggerating the reactions of a cartoons character (Fig. 5): the character's hair is on fire, smoke is coming out of its nose and ears.
Exaggeration, to be visually effective, must overstate extravagantly, enlarging its expression far beyond the truth in order to heighten and amplify.

Hothothot (www.hothothot.com) is another website selling hot sauce that has developed its own humorous visual style based on the concept "hot". The products are represented as "poster" pictures that are parodies of horror films and erotic B movies associated with hot, e.g. "The Road to Hell". Moreover, other designs and site characteristics reinforce this feeling: background colour is red, flames are used for spices and chilli peppers for ingredients.

Humorous style can be created through the use of parody or mimicry thus by borrowing or imitating different periods and genres, such as art, television or cartoon. In a site selling mystery novels, crime is represented as a knife through a bleeding computer, and writers' awards as a tombstone with the mention "Rest In Peace", etc. By borrowing a certain art style, the designer alluded to the association that the known artist came to have. In the age of branding, style is valued for bringing a sense of distinction and identity to products and services.
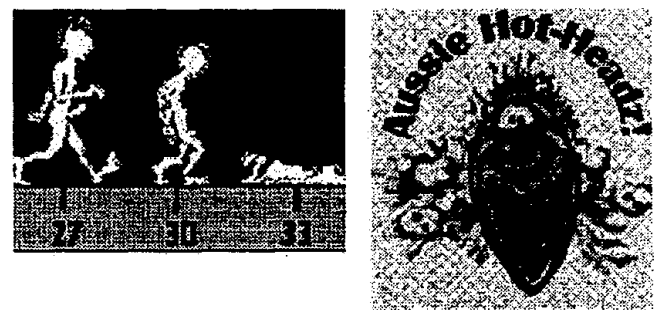

Figure.4. Kilroy

Figure 5. Hot-headz

\section{Case study in electronic shopping}

Two small websites have been selected to show the importance of visual persuasion in electronic shopping. They also show how visual arguments and humour can be used effectively to sell products (Parvo), and how emotions created through a site's appearance, and specific visual messages can captivate viewers, and contrast the site from its potential competitors (FoodNet)

\subsection{Parvo}

Parvo is a very small site selling a unique type of products i.e. specially reinforced shoes. The site is constructed around a very clear and strong message "If 
you want to appear taller then buy Parvo shoes, shoes with a hidden insole." The visual argument is built very logically in a number of steps (i.e. on each web page).

On the home page, the protagonists are set (e.g. the happy couple; see Fig. 6.a). The slogan "Want to be taller?" accompanies the image. In the next two pages the mystery is solved. The solution is given by a juxtaposition of two images (antithesis) picturing difference in sizes between the characters. The difference in size is greatly exaggerated in a humorous way (Fig. 6b). The solution to this transformation is given on another page showing how the shoes are made. By then, anyone wanting to appear taller should be convinced of the usefulness of Parvo shoes. Last pages are the order pages.

Parvo is not only supported by a very clear marketing message, but is also built on a strong narrative structure. Classical narrative is often spoken of as having a beginning, middle and an end. It derives from the threeact play structure and the form of the 19th century novel. The beginning establishes location, character and the main plot points, and the middle produces variations on the plot points and prepares for resolution in the final part. As we can see, the structure of Parvo is very close to the classical narrative structure. The home page introduces the characters and the plot ("Want to be taller?") leading to the resolution of the plot in the next few pages, and the 'happy' ending of buying the shoes. Thus, story telling can provide a very clear framework for the development of electronic shops.
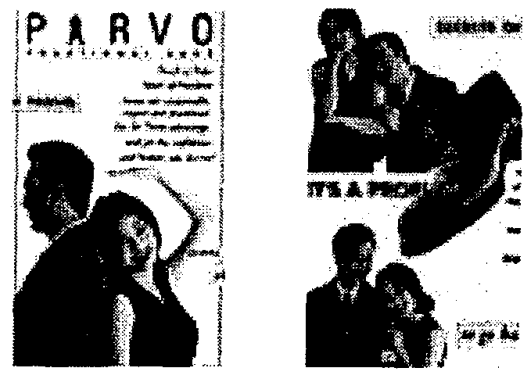

Figures $6 \mathrm{a}$ and $6 \mathrm{~b}$. Parvo

\subsection{FoodNet}

FoodNet is a small prototype website developed for a course in multimedia and electronic commerce. The project's rationale was to develop a website for an alternative food service for the university staff and students, as the service provided by the university was poor. The core of this service is to provide snacks that are delivered around the campus. The site is supported by an appropriate choice of visual style, marketing messages and features such as discounts and sweepstakes. In this site, a deliberate attempt has been made to make the site fun in order to combat the bleakness of canteen food, and thus appealing to potential consumers, and contrasting it with its competitors.

The site design is based on the language of comedy. The initial animation sets the scene by making an emotional promise as to the quality of the site ('humour, fun'). Techniques described above are used in the food illustrations. One can see the incongruity of sandwich ingredients, the utilisation of personification for the French fries (Fig. 7a), and exaggeration of a chopstick picture, representing the Chinese box. Comedy and humour are also at the heart of another animation (where the concept of eating is represented as a page being eaten, in Fig. 7b) to induce consumers to participate in a sweepstake. The students have developed a coherent vocabulary to make the site pleasant and exciting. In this site, the persuasive strategy 'play and fun', having been set through the initial animation, is fulfilled at different points in the sites, and is attained through the enjoyment of the service's food.

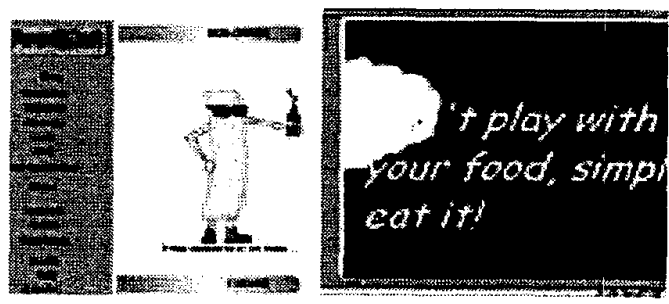

Figures $7 \mathrm{a}$ and $7 \mathrm{~b}$ FoodNet

\subsection{Future designs}

We can create seductive and effective sites, by organising the information in the most efficient and persuasive manner, and by setting a mood to attract and engage viewers so that they interact with the site and ultimately purchase. To achieve this aim designers can use a number of techniques borrowed from graphic design, storytelling and metaphorical imagery. The design of persuasive site can be achieved by defining a unique visual style, by manipulating specific visual variables, and by the choice of visual imagery to achieve a specific communicative goal and induce appropriate emotions. 


\section{Evaluation of persuasive sites}

Once the site has been designed, it could be interesting to investigate viewers' reaction to persuasive sites. We wanted to see if web users react more strongly to certain types of imagery and design factors (i.e. as presented in this paper), and whether it had an impact on the emotional characteristics of the site. A persuasive evaluation should also serve to assess consumers' reactions to the site. Thus, a pilot study concerned with evaluation of home pages is presented. The pilot study is introduced first, including its background, procedure and participants; then results and future studies are discussed.

\subsection{Pilot study}

Forceville [1] reports how subjects interpret three IBM billboards, confirming that imagery based on visual metaphor directs viewers associations and emotion. McQuarrie and Glen [19] demonstrate the positive impact of rhetorical devices (such as visual pun) on consumer elaboration resulting in positive judgements toward the communication.

A study of advertising [20] shows that the emotional content of ads predicted pleasure responses and a positive attitude toward the ad and brand. In other words, emotional ads were perceived favourably and generated better responses. Kim and Yun Moon [21] assess the feeling of trustworthiness in relation with visual design factors. They report that design factors have significant effects upon the emotions. These studies have been used as a guide for investigating the impact of persuasive sites on viewers.

In the pilot study, we wanted to find confirmation of a link between design and emotion, especially regarding humour and enjoyment, which are aspects often ignored in World Wide Web interfaces. We were concerned with finding indications that viewers form associations and inferences from what they see, especially regarding visual metaphors (taken in an inclusive way); these inferences have an impact on the kind of emotions evoked.

A small focus group was first organised where we asked participants to assess designs including Hothothot, and Maison Blanche for their emotional value, likeableness, and associations. On positive results (e.g. Hothothot described as witty, or Maison Blanche as luxurious, and expensive), a pilot study was initiated.
Nine students following an electronic commerce and multimedia course were recruited to participate in the evaluation. Two sites selling the same product, hot sauce, were select for this evaluation. Participants in the evaluation expressed their opinions via completed questionnaires consisting of describing their impressions about each home page in a free flowing manner and then to rate them on an emotional scale.

A list of 13 emotions (awkward, balanced, boring, childish, consistent, dependable exciting, familiar, luxurious, realistic, reliable, vibrant, witty) was determined from Kim and Yun Moon [21] and the focus group. One questionnaire was filled after presentation of each home page, starting with Figure 6 and then Figure 7. The questionnaires and designs were further discussed with the students.

For the pilot study, two very distinctive home pages were chosen: one with a very neutral and symmetric design and with very limited imagery (Fig. 8), the other very colourful and using strong humorous imagery (Fig. 9). The first home page, inspired from Louisiana Blend (www.firemouth.com), consists of the shop name as title, and a series of sauce options characterised by a representation of a pepper and the category names. For the second page, a screen shot of Hothothot was used (as seen in 2.3).

\subsection{Results and discussion}

It is important to note that the sample size of the evaluation is not large enough to draw any statistically accurate conclusions. It was never the intention of the pilot study to perform such an exercise, rather to perform a qualitative study drawing conclusions from answers given by students in the light of studies pertaining to visual persuasion.

The participants' main impressions for Hothothot is "red" and for Louisiana Blend "boring". For Hothothot, the central impressions concern associations with red and imagery of hot as characteristics of the product (hot sauce). For Louisiana Blend, other comments are articulated around three topics: difficulty in identifying the products sold, repetitiveness of the graphics, and association of design with products (a chilli pepper representing hot sauce). On the emotion scale, there is a sharp contrast between the two sites, as can be expected. Hothothot rates high for exciting, vibrant and witty but also awkward. Louisiana generates more neutral answers. 


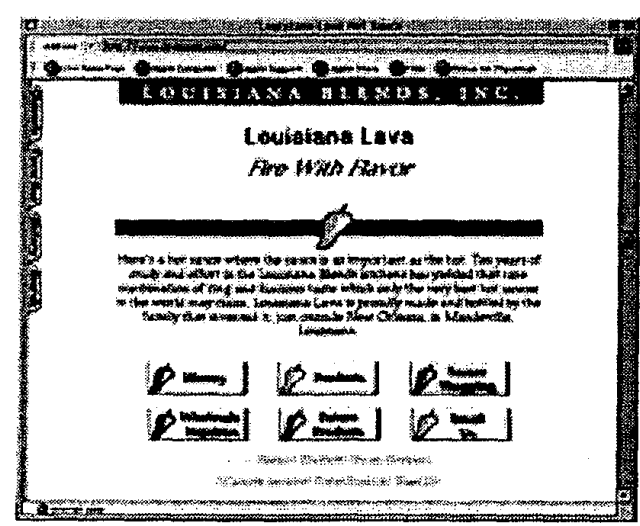

Figure 8. Louisiana blend

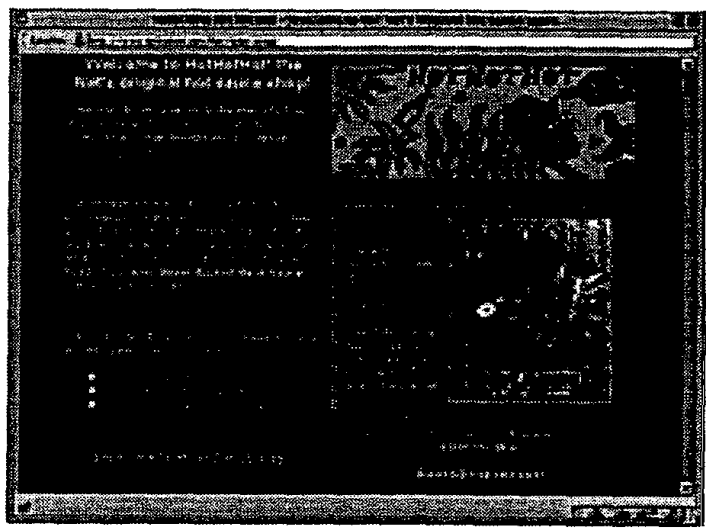

Figure 9. Hothothot
Participants' answers are given only for witty (Fig. 10), and awkward (Fig.11), in order to illustrate the contrast between the two sites. The Likert scales are arranged from "awkward" to "not awkward", "exciting" to "not exciting", and "witty" to "not witty" (answers are given first for Louisiana Blend and then for Hothothot).

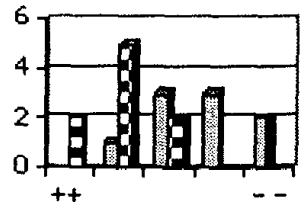

Figures 10. Witty

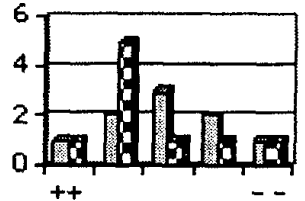

Figures 11. Awkward
The pilot study has shown some indications that viewers form distinctive emotional impressions from the electronic shop design. Participants do interpret and mark specific visual style based on techniques from visual persuasion (parody in poster, and metonymy) with pertinent emotions (witty, vibrant and exciting for Hothothot). They associate meaning with design and rhetorical techniques: red for hot, chilli peppers for hot sauce (metonymy). They also refer to the appropriateness of designs by products sold. Participants were making rhetorical assessment of the site's communicative intent, ("it is an appropriate page for the product sold" Hothothot, "use pimento for remembering the product" Louisiana Blend).

We should carry out similar evaluations with a larger population sample, but also with more test- samples (e.g. pair of home pages). Beside inferences from visual imagery and emotional impact, we should also cover, preferences, intention to visit and purchase. Moreover, further studies could include the assessment of the whole site. However, the purpose of the pilot study was to show that participants react more favourably to specific visual style. This could have serious implications for electronic commerce: in the choice of electronic shop, long term consumer relationship (through enjoyment) and even perception of usability.

\section{Conclusion}

Consumer electronic shopping will complement or replace traditional form of shopping. However, in order to guarantee the success of electronic shopping we need to convince consumers to buy. The central question addressed by this paper was the design of a persuasive electronic commerce site. The aim of this paper was to contribute to the development of effective electronic shopping and supplement discussions in persuasive discourse. In this paper we focused on the role emotion, an aspect seldom discussed in relation to electronic commerce. It has been shown how we can provoke specific emotions, impressions and associations, through specific visual style and appeal, through the portrayal of people, the use of rhetorical technique or the manipulation of some design elements. To substantiate our discussion, we have presented examples and case studies drawn from electronic shopping. Although we have focused on the visual component, a similar approach could be taken with text. Similarly, we should be aware of the relation of text to images. 
Some studies have concentrated on the relation between headline and images, showing for example how pun could be created through the combination of title and graphics [22].

We have presented mainly emotions related to enjoyment and pleasure. However, we need to refine these findings to include a larger spectrum of emotions adapted to electronic commerce. We should create an emotional environment, appropriate for the products sold and the consumer target. In the highly competitive web environment, it is imperative to insure that viewers form favourable impressions of electronic shops. Two sites might sell the same kind of products but may not be equally persuasive.

To supplement this study, we have moved from the design aspect to consumer perceptions. We have seen that consumers form more favourable impressions and different associations or emotions from specific design factors or imageries. Thus, integrating this dimension in the design and assessment of electronic shops could prove crucial to the success of electronic commerce.

There are several directions for research in this domain, especially with regard to usability and persuasion. We see a complement between usability and persuasive evaluation, both necessary elements of web assessment. We also have to guarantee that sites are usable to facilitate purchase. We need to study in more depth the effect of emotions, consumer perceptions, and ease of use. Thus, we need to integrate usability and persuasive studies in the same framework.

\section{References}

[1] Messaris P. (1996) Visual persuasion: the role of image in advertising Sage Publications: Califomia.

[2] Forceville (1996) Pictorial metaphor in advertising. Routledge: London.

[3] Durand, J. (1987) Rhetorical figures in the advertising Image. In Marketing and Semiotics: New directions in the study of signs for sale, ed. J. Umiker-Sebeok, 295-378.

[4] Hirschman E.C. and Holbrock M.B. (1982) Hedonic consumption: emerging concepts, methods amd propositions. Journal of Marketing, 46, 92-101.

[5] Holbrook M. and M. Gardner (1998) How motivation moderates the effects of emotions on the duration of consumption (1998) Journal of business research 42, 241-252.
[6] Lijander V. and T. Strandvik (1997). Emotions in service satisfaction. International Journal of Service Industry Management, 8, 2, 33-43.

[7] Mackay K. and D. Fesenmaier (1997) Pictorial element of destination in image formation. Annals of Tourism research 24, 3, 537-565.

[8] Babin B., Darden M. and Griffin M. (1994) Work and /or fun: measuring hedonic and utilitarian shopping value. Journal of consumer research 20, 644-655.

[9] Saint-Hilaire L.(1997) L'image un moyen de communication. In Comment faire des images qui parlent, Les editions Transcontinental: Montreal Partiel 52-61

[10] Wilde Visual literacy

[11] Dondis A. A primer of visual literacy. MIT Press: Cambridge.

[12] Scott L. (1994) Images in advertising: the need for a theory of visual rhetoric. Journal of consummer research, 17, Sept, 252273.

[13] Dormann C. (1997) Persuasive interface: Designing for the WWW. IEEE international professional communication conference, Salt Lake city, 345-354.

[14] Dyer G. (1992) Advertising as communication.Routlege: London.

[15] Caudle F. (1990) Communication and arousal of emotion: some implications of facial expression research for magazine advertisments. In emotion in advertising eds S. Agres, J. Edell and T. Dubtsky. Quorum books: London 127-159.

[16] Baker (1961) Visual persuasion. McGraw Hill: New York.

[17] Spots H., Weinberger M., and A. Parsons (1997) Assessing the use and impact of humour on advertising effectiveness: a con tigency approach. Journal of advertising $26,3,17-31$.

[18] Velthoven W., Liesbeth den Boer, Strengholt (1997) Website graphics. Thames and Hudson: London.

[19] McQuarrie E. and Glen M. (1999) Visual rhetoric in advertising: text-interpretive, experimental, and reader-response analyses. Joumal of consumer research, 26, 37-53.

[20] Thorson E., Chi A. C. Leavitt (1992) Attention, memory, attitude, and conation: a test of the advertising hierarchy. Advances in consumer research, 19, 366-379.

[21] Kim J. and J. Yun Moon (1998) Designing toward usability in costumers-trustworthiness of cyber-banking system interfaces, 10, 1-29.

[22] McQuarrie and Glen M. (1992) On Resonnance: A critical pluralistic Inquiry into advertising rhetoric Journal of consummer research.

http://scuish.scu.edu/SCU/Departments/Marketing/faculty/mcqst uff/reson55.htm 